\title{
Designing a omnichannel closed loop green supply chain network adapting preferences of rational customers
}

\author{
T NIRANJAN*, P PARTHIBAN, KARTHIK SUNDARAM and PRAVIN NATH JEYAGANESAN
}

\begin{abstract}
Department of Production Engineering, National Institute of Technology, Tiruchirappalli 620015, India
e-mail: niranjanthir@yahoo.com; parthee_p@yahoo.com; karthik.sun95@gmail.com;

pravinnathnitt@gmail.com
\end{abstract}

MS received 22 July 2018; revised 10 October 2018; accepted 18 October 2018; published online 9 February 2019

\begin{abstract}
The manufacturing industry in India started moving towards multi channel supply chain for delivering products to the customer by his preferred channel of purchasing. But firms are far behind to achieve a goal of omnichannel where there exists better interface between various channels which increases their customer range and customer comfort. Also, today consumer awareness had increased with respect to environmental protection while at the other end the government rules and regulations also force firms to go with adopting sustainability concepts like green and recycling processes in supply chains. This work deals with this major issue faced by the firms in India that how to integrate multiples channels in designing their supply chain network considering economic and environmental sustainability simultaneously. This paper presents a mathematical model for an integrated multi channel closed loop supply chain network problem, the modeling decisions that include the selection of the entity that will fulfill the demands of the omni channel customer during different time periods and the supplier selection process integrated with the production amounts, inventory levels, stockouts and shipment quantities. The aim of the model is to minimize the total cost incurred to the customer, total cost incurred in running the supply chain and minimize the total pollution emissions from all the transportations of the products between the different stages of the supply chain. It is a mixed integer programming problem considered for a leading kitchenware company in southern part of India and solved using IBM CPLEX optimizer. The result shows that how the dynamics of omni channel customer options affects the optimal supply chain structure.
\end{abstract}

Keywords. Omni channel; multi period; closed loop; optimization; green; supply chain.

\section{Introduction}

The development in Information Technology leads to a development in the new way of doing sales, marketing and promotion of products called E-Commerce or E-Business. It is paperless communication of information related to business, online shopping, online transactions, bonds \& stock exchange, paying bills of daily necessities, etc. According to reports of Indian Brand Equity Foundation (IBEF), Indian online market reached from $\$ 3.9$ million in 2009 to $\$ 38.5$ billion in 2017 and is expected to rise to $\$ 200$ billion by 2026 which is mostly triggered by a rise in internet penetration which grew from just $4 \%$ in 2007 to $35.03 \%$ in 2017. Still, a large proportion of the population is unserved and hesitate to order online and to serve people of different demographics and cohorts every firm is trying to sell their products through all modes. Motorola and Xiaomi which started its operation by selling their product online

*For correspondence (single channel) now start selling product through different online partners and in offline mode too (multichannel). But are far behind to achieve a goal of omnichannel Supply Chain. However, Hospitality and Tourism Sector booking of Airlines, Hotels, Railways and Buses, etc. are either successful in achieving omnichannel or on the verge of attaining it. This can be predicted to be the future of supply chain networks for manufacturing industry too as most of the firms today are trying to shift themselves from multichannel to omnichannel.

Today customers expect to purchase material whenever and wherever possible. Therefore, a versatile SC network is very essential. Though a multi-channel supply chain can make sure the product reaches the customer, the existence of each channel as individual entities slows the process down. If there exists a good interface between various channels, it will drastically increase the customer comfort and the sales. This type of an interlinked network is called an Omni channel network. Omni channel supply chain consists of several modes for the 
customer to choose from, to receive their product, where each having its own carbon footprint, incurred cost and lead time.

A forward supply chain deals with sourcing, raw material conversion to the product, etc., until the distribution of the finished item to buyers. A reverse supply chain starts from the end customer and encounter different decision points until it reaches the point of remanufacturing or repairing. When reverse logistics is combined with forward logistics it becomes a closedloop supply chain. A closed-loop supply chain model involves the collection of the returned products and making sure that the product reaches the manufacturer for recycling and reuse, reducing exploitation of resources. Green logistics model acts as an excellent marketing strategy because of the increasing environmental consciousness. The firm can also get several Government subsidizations for providing better carbon foot print.

This study proposes a Mixed Integer Programming model for optimizing a Closed loop green Supply Chain network comprising of manufacturing centres, customer zones and re-collection facilities. The products are tested for quality and are sorted in collection centres to be recycled or to be disposed. Recyclable materials are separated and are carried to plants for remanufacturing. In this work, multiple channels like online direct delivery, pickup at retailer, retailer sales are considered for a leading kitchenware company in southern part of India is chosen to evaluate the benefits of Omni channel Supply chain. With the increased visibility of the price options, Customers in the modern world are highly responsive to the price options. Customer pricing options have been entangled to design a wholistic network.

The rest of the paper is organised in the following manner. Section 2 provides the comprehensive review of the relevant existing literature. The problem description and model formulation are given in section 3. Section 4 deals with results and discussion. Finally, the conclusion and some future extensions are given in section 5 .

\section{Literature review}

Major issues with conventional distribution network pointed out by Swaminathan et al [1] where they mentioned about the ways to deal with e-commerce fulfillment. They concluded that a centralized control is a very important in integrating channels which would provide better efficiency, profitability, lead to reduced inventory and provide better customer satisfaction. Another important paper on supply chain integration considering e-business was by Agatz et al [2]. This paper focused on important paradigms of designing of network and inventory and managing of inventory and capacity. They also mentioned the trade-off between the pooling of inventory and the efficiency of delivery. Lal et al [3], also emphasized the requirement of net based channels and they showed that internet channels help firms to increase their profits under certain situations by studying different distribution scenarios. King et al [4] and Bernstein et al [5] made a conclusion that cost difference for operating the second channel is not much high then operating a multichannel supply chain would be feasible. Farahani et al [6] studied about the decision-making in a three-echelon supply chain. The model involves multiple retailers, whole sale points and product varieties. It involves both direct and indirect channels in reaching the customer. Biswas et al [7] proposed a model considering minimization of aggregate cost of the framework focused on multi product and multi period as the conditions for demonstrating. The target capacity is to limit the aggregate cost which incorporates the opening and transportation costs.

Fleischmann et al [8] formulated a model out of genetic algorithm for attaining the ideal design reverse supply chain network which involved dismantling centres, reprocessing plants and distribution warehouses. The authors concluded from the result of optimal solution there is a high correlation between demands and return volumes. Amin et al [9] aimed to develop a MILP deterministic model for optimizing a closed-loop supply chain. The formulation is applied to copier remanufacturing. Elements of uncertainties are not considered since a deterministic model is used. Keyvanshokooh et al [10] proposed an accelerated stochastic Benders decomposition algorithm to model qualitatively various uncertainties and solve the combinatorial problem. On the downside, it considers only a single product and single objective of profit maximization. Gaur et al [11] have however, concentrated on the tactical issue of network configuration. The integrated optimization model determined optimum sales amount, production plan and design.

Eldehli et al [12] discussed a formulation, which deals with a green $\mathrm{SCN}$ considering the carbon dioxide emissions along with fixed and variable location costs. In order to simplify the problem legrangian relaxation is applied, simplifying the problem in two easily solvable parts. Tao et al [13] analyses optimal behavior of various players on the basis of complementary theory and variational inequality where two kinds of carbon emission were included and carbon tax is taken to be an endogenous variable. Lam et al [14] introduced a mathematical model having two objectives for optimizing port hinterland intermodal network to minimize transportation time as well as overall cost. This model provides an idea of how to plan the network in changing carbon emission restrictions. Nouira et al [15] showed a correlation between green performance of an item and its customer demand. It gives MILP models for both upstream and downstream supply chain. Colicchia et al [16] showed that supply chain optimization based on cost reduction objective can lead to 
facilitation of green objectives. If a small increase in distribution cost can lead to a great move towards green objective, then such a change is justified.

Cummins et al [17] opined omni channel as a framework involving all buyer-seller touch points in a single interaction mechanism. The developed omni channel model considers factors such as sales, technology impact, effect on firm performance, sales processes, effect on relationships and the effect on various communication tools and platforms. Picot-Coupey et al [18] provided a comprehensive and longitudinal approach to explore the shift from multi- to omni-channel and suggests guidelines for the process. Hübner et al [19] focused on a logistic perspective for grocery SC rather than customer or service aspects alone. An integrated strategic planning network is developed to provide a structural element for planning areas and trade-offs for fulfilling. The model is also transferable to retail industries other than grocery. Bortolini et al [20] proposed an amalgamated method for planning of multi modal Fresh Food Distribution Networks (FFDNs) which provides the professionals, a template on which further planning of FFDN can be done considering three objectives i.e., total cost, delivery time and carbon footprint.

Mogale et al [21] presented a novel integrated multiobjective, multi-modal and multi-period mathematical model for grain silo location-allocation problem to reduce the total supply chain cost and the lead time. Mogale et al [22] addressed the issue when a number of markets are separated geographically each having a locally different demand pattern, but produce or transport between the different markets, the same common component, the objective solved for is the decision between the 2 options whether to manufacture locally or transport between markets, given, the final assemblies are localized. Costantini et al [23] Provided systematic quantitative evidence of eco-innovation on two channels (direct and indirect) through which the generation and diffusion of green technologies affect environmental performance. Case study of European industries were considered. Arampantzi et al [24] proposed a new MMILP model that incorporates cost (investment, operational), environmental (emission quantity, waste generation), social (employment opportunities, improved labour conditions, prioritising community development). They also discussed in detail the applications of this model for global manufacturers.

From the literature study, it was found that most mathematical models of supply chain did not integrate the aspects such as customer preferences of multiple channels in a supply chain, multichannel inventory and transportation costs for a closed loop supply chain, supplier selection for a multi period production network and the impact of carbon emissions simultaneously. To overcome this deficiency, in this work, an integrated multi-Channel (omni channel) supply chain network reflecting real- life industrial scenarios is considered.

\section{Problem description and model formulation}

\subsection{Problem description}

A leading kitchenware company in India is chosen to evaluate the benefits of Omni Channel closed loop Supply chain. For evaluation purpose, the network of the firm's supply chain for a small region in southern part of India is selected. Since each customer cannot be considered, the concept of customer clustering has been incorporated. To realize the omni channel, three types of customers are being considered. By means of this, a strong link between retailers and online partner is realized. The amount of products returned will be fixed based on a survey. Three suppliers, three manufacturers, three warehouses, three retailers, three collection centers and five customers each of the three demand types are considered. To reduce the complexity of the problem, it is assumed that no of products manufactured by the firm is one and no of raw materials purchased from the suppliers also one. The entire supply chain is solved over multiple instances (ten instances). It is assumed that it takes one time period to transport the product and the raw materials between the consecutive echelons. Inventory is present at the warehouse, retailer and the recycling center. Figure 1 depicts a schematic representation of assumed supply chain.

\subsection{Model formulation}

The index set that will be used in the model formulation are defined below

$$
\begin{array}{lc}
\text { 3.2a Sets: } & \\
\text { I: } & \text { Set of suppliers }(\mathrm{i}=1,2, \ldots, \mathrm{I}) \\
\mathrm{J}: & \text { Set of plants }(\mathrm{j}=1,2, \ldots, \mathrm{J}) \\
\mathrm{L}: & \text { Set of distributors }(1=1,2, \ldots, \mathrm{L}) \\
\mathrm{M}: & \text { Set of retailers }(\mathrm{m}=1,2, \ldots, \mathrm{M}) \\
\mathrm{F}: & \text { Set of customers }(\mathrm{f}=1,2, \ldots, \mathrm{F}) \\
\mathrm{Q}: & \text { Set of collection points }(\mathrm{q}=1,2, \ldots, \mathrm{Q}) \\
\mathrm{S}: & \text { Set of Products }(\mathrm{s}=1,2, \ldots \mathrm{S}) \\
\mathrm{K}: & \text { Set of raw materials }(\mathrm{k}=1,2, \ldots, \mathrm{K}) \\
\mathrm{T}: & \text { Time Period }(\mathrm{t}=1,2, \ldots, \mathrm{T})
\end{array}
$$

\begin{tabular}{|c|c|c|}
\hline $\begin{array}{l}\text { c(offline/online } \\
\text { customers) }\end{array}$ & (COP): & $\begin{array}{l}\text { Set of online/offline customers } \\
\text { preferring whichever is cheaper }\end{array}$ \\
\hline $\begin{array}{l}\mathrm{d} \text { (online } \\
\text { customers) }\end{array}$ & $(\mathrm{CO})$ : & $\begin{array}{l}\text { set of online customers preferring } \\
\text { direct delivery }(\mathrm{co}=1,2, \ldots, \mathrm{CO})\end{array}$ \\
\hline $\begin{array}{l}\text { e(offline } \\
\text { customers) }\end{array}$ & $(\mathrm{CS})$ : & $\begin{array}{l}\text { set of Retail customers who prefer to } \\
\text { receive from Retailers irrespective } \\
\text { of time taken based on availability } \\
\text { at the stores (cs }=1,2, \ldots, \mathrm{CS})\end{array}$ \\
\hline
\end{tabular}

3.2b Subset of customers $(F)$ :

3.2c Parameters:

$P_{i k}^{\max }: \quad \quad$ Maximum capacity of $\mathrm{i}^{\text {th }}$ supplier for $\mathrm{k}^{\text {th }}$ raw material $P_{i k}^{\min }: \quad \quad \quad$ Minimum capacity of $\mathrm{i}^{\text {th }}$ supplier for $\mathrm{k}^{\text {th }}$ raw material 


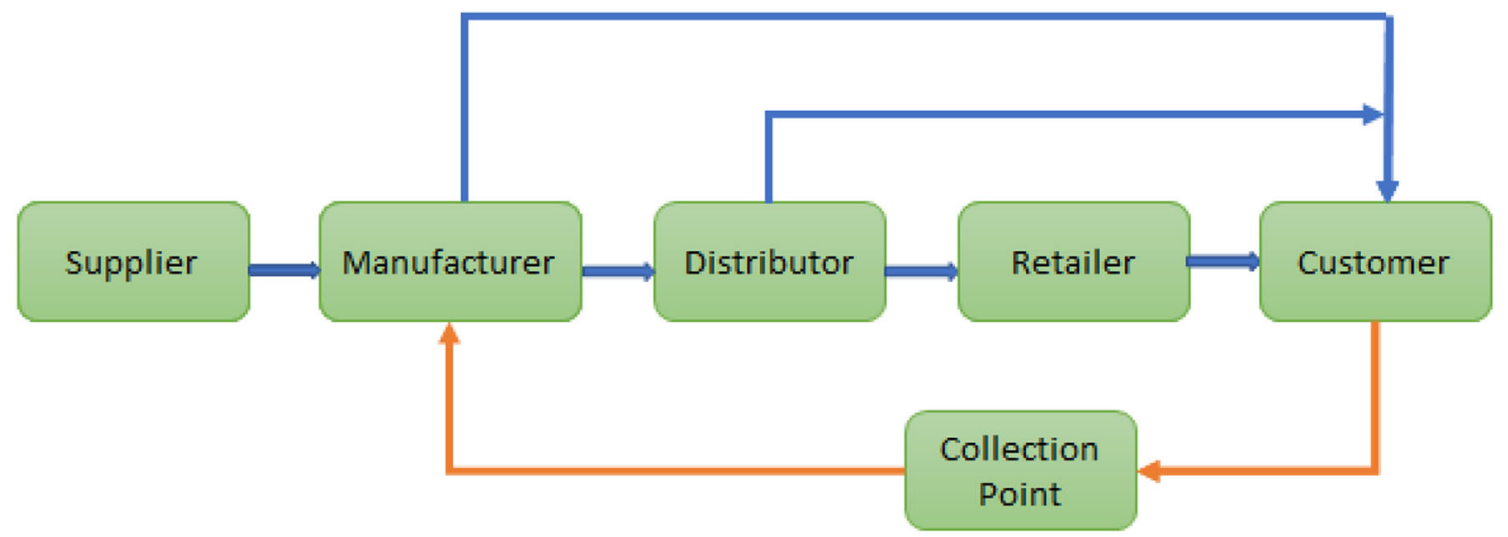

Figure 1. Schematic representation of supply chain.

\begin{tabular}{|c|c|}
\hline$C_{i k}$ & $\begin{array}{c}\text { Purchasing Cost of raw material ' } k \text { ' from supplier 'i' } \\
\text { per unit }\end{array}$ \\
\hline$R_{s k}:$ & Requirement of raw material $\mathrm{k}$ for product $\mathrm{s}$ \\
\hline$T_{i j}:$ & $\begin{array}{c}\text { Transportation cost from supplier 'i' to plant ' } \mathrm{j} \text { ' per } \\
\text { unit }\end{array}$ \\
\hline$P_{j s}:$ & Capacity of plant $\mathrm{j}$ \\
\hline$P C_{j s}:$ & Production cost of product 's' per unit at plant $\mathrm{j}$ \\
\hline$D_{a}:$ & demand of product 's' by customer 'COP' at time ' $\mathrm{t}$ ' \\
\hline$D_{b}:$ & demand of product ' $\mathrm{s}$ ' by customer ' $\mathrm{CO}$ ' at time ' $\mathrm{t}$ ' \\
\hline$D_{c}:$ & demand of product ' $\mathrm{s}$ ' by customer 'CS' at time ' $\mathrm{t}$ ' \\
\hline$D L_{s}:$ & Maximum capacity of inventory at Distributor \\
\hline$D^{\operatorname{IniInv}}:$ & Initial inventory at Distributor \\
\hline$T_{j l}:$ & Transport cost from plant ' $\mathrm{j}$ ' to distributor ' $\mathrm{l}$ ' per unit \\
\hline$D_{c l}^{I n v}:$ & Holding cost of product 's's per unit at Distributor \\
\hline$R t_{m}:$ & capacity of Retailer 'm' \\
\hline$R^{\operatorname{InitIn} v}$ & Initial inventory of Retailer \\
\hline$P^{s p}:$ & Manufacturer Selling price (at plant) \\
\hline$D^{s p}:$ & Distributor Selling price \\
\hline$R^{s p}:$ & Retailer Selling price \\
\hline
\end{tabular}

$d_{\text {if }}$ :

$d_{l f}:$

$d_{l m}:$

$T_{j f}:$

$T_{l f}:$

$T_{l m}:$

$R_{c}^{I n v}$

$R^{\text {REitInv }}$ :

$E_{\text {cop }}$ :

$E_{c o}:$

$E_{c s}:$

$R E C^{\max }$ :

$T R_{q j k}$ :

$R E C_{c}^{I n v}:$

$R E C C$ :

$E M$ : distance between plant and customer

distance between distributor and customer

distance between distributor and customer

Transportation cost to customer per unit distance from plant ' $\mathrm{j}$ '

Transportation cost to customer per unit distance from distributor

Transportation cost of the finished product from the distributor to the retailer per unit Retailer's Holding cost

Initial inventory at collection center

Quantity returned back by customer 'cop'

Quantity returned by customer 'co'

Quantity returned by customer 'cs'

Collection center maximum capacity

Transport cost of raw material ' $k$ ' from collection ' $q$ ' center to plant ' $\mathrm{j}$ ' per unit

Collection center's holding cost

Recycling cost per unit of raw material at collection center

Emission per unit distance between $\mathrm{p}$ and $\mathrm{r}$

$$
(p, r \in i, j, m, l, f, q)
$$

Dis :

Veh:

EV :

Distance between $\mathrm{p}$ and $\mathrm{r}(p, r \in i, j, m, l, f, q)$ vehicle capacity between $\mathrm{p}$ and $\mathrm{r}(p, r \in i, j, m, l, f, q)$

Emission cost per unit pollution

3.2d Decision variables:

$W_{i, k}^{t}$ : Quantity of raw material ' $\mathrm{k}$ ' ordered by the manufacturer(plant) to supplier ' $i$ '

$P_{i}^{b i n, t}: \quad \quad\{1$ if supplier $i$ is selected

0 if supplier $i$ is not selected

$A_{i, j, k}^{t}$ : Quantity of raw material k flowing from supplier

i to Plant $\mathrm{j}$

$A_{s}^{t}$ : $\quad$ Quantity of raw material reaching manufacturer

$B_{j, s}^{t}$ : $\quad$ Quantity of product 's' produced at plant ' $\mathrm{j}$ '

$B_{j, l, s}^{t}$ : Quantity of finished products s flowing from Plant $\mathrm{j}$ to distributor 1

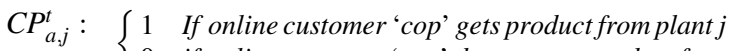

$\left\{\begin{array}{l}\text { if online customer 'cop' doesnot get product from plant } j \\ \text { if }\end{array}\right.$

$C P_{b, j}^{t}:\{1$ If online customer 'co' gets product from plant $j$

0 if online customer 'co' doesnot get product from plant $j$

$\mathrm{ID}_{\mathrm{s}} \quad$ Inventory quantity at Distributor

$C_{l, m, s}^{t}$ : Quantity of finished product 's' flowing from distributor 1 to retailer $\mathrm{m}$ during

$C D_{a, l}^{t}: \begin{cases}1 & \text { If online customer 'cop' gets product from distributor } l\end{cases}$

0 if online customer 'cop' doesnot get product from distributor $l$

$C D_{b, l}^{t}:\{1$ If online customer 'co' gets product from distributor $l$

0 if online customer 'co' doesnot get product from distributor $l$

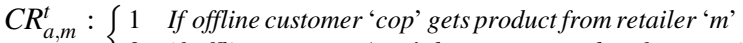

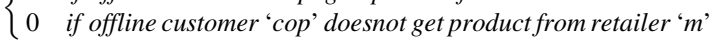

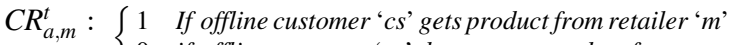

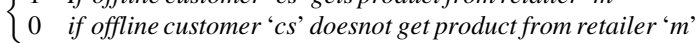

$I R_{s}^{t}: \quad \quad$ Inventory quantity at retailer

$I C_{k}^{t}: \quad \quad$ Inventory quantity at collection center

$H_{q, k, j}^{t}$ : Quantity of raw material k flowing from collection point $\mathrm{q}$ to plant $\mathrm{j}$

\section{2e Objective function:}

Minimize

Purchasing costs - The total purchasing cost of the raw material (TRPC) can be determined as follows:

$$
T R P C=\sum_{i} \sum_{k} \sum_{t}\left(C_{i, k} * W_{i, k}^{t}\right)
$$


Manufacturing costs - The total cost (TMC) associated with manufacturing the products can be determined as follows:

$$
T M C=\sum_{j} \sum_{s} \sum_{t}\left(P C_{j, s} * B_{j, s}^{t}\right)
$$

Transportation cost - The total transportation cost (TTC) incurred by the product flow across the echelon

$$
\begin{aligned}
T T C= & \left.\sum_{j} \sum_{l} \sum_{t}\left(T_{j, l} * B_{j, l}^{t}\right)\right)+\sum_{i} \sum_{j} \sum_{t}\left(T_{i, j} * A_{i, j}^{t}\right) \\
& +\sum_{l} \sum_{m} \sum_{t}\left(T_{l, m} * A_{l, m}^{t}\right)+\sum_{q} \sum_{j} \sum_{k}\left(T R_{q, j, k}\right. \\
& \left.* H_{q, k, j}^{t}\right)+\sum_{c o p} \sum_{j} \sum_{t}\left(\left(C P_{j, c o p}^{a} * D_{a, c o p}^{t}\right.\right. \\
& \left.\left.*\left(T_{j, c o p, t} * d_{c o p, j}\right)\right)\right)+\sum_{c o p} \sum_{l} \sum_{t}\left(\left(C D_{a, l, c o p}\right.\right. \\
& \left.* D_{a, c o p}^{t} *\left(\left(T_{l, c o p, t} * d_{l, c o p}\right)\right)\right) \\
& \left.+\sum_{c o} \sum_{l} \sum_{t}\left(\left(C D_{b, l, c o} * D_{b, c o}^{t}\right) *\left(T_{l, c o, t} * d_{c o, l}\right)\right)\right)
\end{aligned}
$$

Inventory carrying costs - The total inventory carrying cost (TIC) in the supply chain include the carrying cost of raw materials at the recycling center, carrying cost of product at the distributor and retailer.

$$
\begin{aligned}
T I C= & \sum_{l} \sum_{t}\left(D_{c, l}^{I n v} * I D_{s, l}^{t}\right)+\sum_{m} \sum_{t}\left(R_{c, m}^{I n v} * I R_{s, m}^{t}\right) \\
& +\sum_{q} \sum_{t}\left(R E C c_{q}^{I n v} * I C_{k, q}^{t}\right)
\end{aligned}
$$

Online customer cost - The cost associated with products which are ordered online by the customer (OCC).

$$
\begin{aligned}
\text { OCC }= & \sum_{\text {cop }} \sum_{j} \sum_{t}\left(\left(C P_{j, \text { cop }}^{a} * D_{a, \text { cop }}^{t} * P_{j}^{s p}\right)\right) \\
& +\sum_{c o p} \sum_{l} \sum_{t}\left(\left(C D_{a, l, \text { cop }} * D_{a, \text { cop }}^{t} * D_{j}^{s p}\right)\right. \\
& \left.+\sum_{c o} \sum_{l} \sum_{t}\left(\left(C D_{b, l, c o} * D_{b, c o}^{t}\right) * D_{l}^{s p}\right)\right)
\end{aligned}
$$

Retail customer cost - The cost associated with products bought from retailer (RCC).

$$
\begin{aligned}
R C C= & \sum_{c o p} \sum_{m} \sum_{t}\left(C R_{a, m, c o p} * D_{a, c}^{t} * R_{k}^{s p}\right) \\
& \left.+\sum_{c s} \sum_{m} \sum_{t}\left(C R_{b, m, c s} * D_{c, c s}^{t} * R_{k}^{s p}\right)\right)
\end{aligned}
$$

Recycling cost - Cost incurred in recycling the product and converting it into raw materials in the collection center (RECC).

$$
R E C C=\sum_{q} \sum_{j} \sum_{t}\left(H_{q, j, t} * R E C c_{q}\right)
$$

Pollution cost - Pollution cost incurred during material flow between various echelons of the network (CPOLL).

$$
\begin{aligned}
C P O L L= & E V *\left(\sum_{i} \sum_{j} \sum_{t} \frac{\left(E M_{i, j} * D i i_{i, j} * A_{i, j}^{t}\right)}{V e h_{i, j}}\right. \\
& +\sum_{j} \sum_{l} \sum_{t} \frac{\left(E M_{j, l} * D i s_{j, l} * B_{j, l}^{t}\right)}{V e h_{j, l}} \\
& +\sum_{l} \sum_{m} \sum_{t} \frac{\left(E M_{l, m} * D i s_{l, m} * C_{l, m}^{t}\right)}{V e h_{l, m}} \\
& \left.+\sum_{q} \sum_{i} \sum_{t} \frac{\left(E M_{q, j} * D i s_{q, j} * H_{q, j}^{t}\right)}{V e h_{q, j}}\right)
\end{aligned}
$$

According to the specified costs in the supply chain, the objective functions are given by the following equation:

Phase 1 (To find the choice of rational Customer)

$$
\text { Minimize Customer Cost }=O C C+R C C
$$

Phase 2 (To find the optimal network based on the rational choice)

$$
\begin{aligned}
\text { Minimize Supply Chain Cost }= & \text { TRPC }+ \text { TMC }+ \text { TRTC } \\
& +T I C+R E C C+C P O L L
\end{aligned}
$$

\section{2f Constraints:}

Phase 1:

The following constraints assign the customer to the most economic option available (online or offline), assuming full visibility of pricing options and rational nature.

$$
\sum_{j} C P_{a, j, c o p}+\sum_{l} C D_{a, l, c o p}+\sum_{m} C R_{a, m, c o p}=1 \quad \forall c o p
$$

For the customer who prefers online products.

$$
\sum_{j} C P_{b, j, c o}+\sum_{l} C D_{b, l, c o}=1 \quad \forall c o
$$

For the customer who prefers offline products.

$$
\sum_{m} C R_{b, m, c s}=1 \quad \forall c s
$$

Phase 2:

The constraints involved in the model are as follows:

Order from manufacturer should be within the minimum and maximum capacity limits of the supplier

$$
\begin{array}{cc}
W_{i, k}^{t} \leq S_{i, k}^{\max , t} * P_{i}^{b i n, t} \quad \forall i, k, t \\
W_{i, k}^{t} \geq S_{i, k}^{\min , t} * P_{i}^{b i n, t} \quad \forall i, k, t
\end{array}
$$

Binary variable associated with the supplier 


$$
\sum_{i} P_{i}^{b i n, t}=1 \quad \forall t
$$

The quantity ordered by the manufacturers must be transported from suppliers to the manufacturers so that the production can be commenced.

$$
W_{i, k}^{t}=\sum_{j} A_{i j k}^{t} \quad \forall i, t, k
$$

Raw material reaching plant before starting production should be equal to the sum of raw materials transported from collection centers and suppliers.

$$
\sum_{i} A_{i j k}^{t-1}+\sum_{q} A_{q j k}^{t-1}=\sum_{l} R_{s k} * B_{j l}^{t} \quad \forall j, t, k
$$

Quantity of each product produced should be limited by its maximum allowed production quantity

$$
\sum_{s} B_{j s}^{t} \leq P_{j s} \quad \forall j, s, t
$$

Quantity manufactured by each manufacturer should be enough to satisfy the demand of online customers ordering directly from plants and warehouses.

$$
\begin{aligned}
& B_{j, s, j}^{t}=\sum_{l} B_{j l}^{t}+\sum_{c o p}\left(C P_{a, j, c o p} * D_{a, c o p}^{t}\right)+\sum_{c o}\left(C P_{b, j, c o}\right. \\
& \left.\quad * D_{b, c o}^{t}\right) \\
& \forall j, t
\end{aligned}
$$

Final inventory at each warehouse after the demand has been satisfied should be less than the warehouse maximum capacity for each product.

$$
I D_{l}^{t} \leq W_{l}^{\max } \quad \forall l, t
$$

Initial inventory at each warehouse and the amount ordered must be enough to satisfy the retailer demand and online customer demand.

$$
\begin{aligned}
D_{1}^{\text {IniInv }} & =I D_{l}^{1}+\sum_{l} C_{l, m, 1} \quad \forall l \\
I D_{l}^{t-1}+\sum_{j} B_{j l}^{t-1} & =I D_{l}^{t}+\sum_{m} C_{l, m, s} \\
& =\sum_{c o p}\left(C D_{a, l, c o p} * D_{a, c o p}^{t}\right) \\
& +\sum_{c o}\left(C D_{b, l, c o} * D_{b, c o p}^{t}\right) \quad \forall l, t
\end{aligned}
$$

The inventory at retailer should be less than the capacity of storing at retailer

$$
R_{m}^{I n v, t} \leq R_{m}^{\max } \forall m, t
$$

Initial inventory and order at each retailer must be enough to satisfy customer offline demand

$$
\begin{aligned}
R t_{m}^{I n t I n v, 1}= & R i n v_{m, 1}+\sum_{c o p}\left(C R_{a, m, c o p} * D_{a, c o p, 1}\right) \\
& +\sum_{c s}\left(C R_{b, m, c s} * D_{a, c s, 1}\right) \\
\forall m, t & \\
R_{m}^{I n v, t-1}+\sum_{l} C_{l m}^{t-1}= & R_{m}^{I n v, t}+\sum_{c o p}\left(C R_{a, m, c o p} * D_{a, c o p}^{t}\right) \\
& +\sum_{c s} C R_{b, m, c s} * D_{a, c s}^{t} \quad \forall m, t
\end{aligned}
$$

Back order quantity at all time periods are assumed to be zero. In other words, all the customer demands must be satisfied at each time period.

Inventory condition for every collection center

$$
\begin{gathered}
R E C_{q}^{\text {IniInv }}=\beta_{q}^{1}+\sum_{j} H_{q j}^{1} \quad \forall q, t=1 \\
\beta_{q}^{t-1}+\sum_{c o p} E_{c o p}^{t-1} * R_{s k}+\sum_{c o} E_{c o}^{t-1} * R_{s k}+\sum_{c s} E_{c s}^{t-1} * R_{s k} \\
=\beta_{q}^{t}+\sum_{j} H_{q j}^{t} \quad \forall q, t, k
\end{gathered}
$$

Final inventory at recycling centre must be limited to the maximum inventory capacity of each recycling centre.

$$
\beta_{q}^{t} \leq R E C_{q}^{\max } \forall q, t
$$

Non-negativity constraints

$$
A_{i j k}, B_{j l s}, C_{l m s} \geq 0
$$

The values of input parameters of the model are shown in table 1 .

\section{Results and discussion}

The model formulated is tested for a set of data and the results are discussed. The intermediate outputs are discussed for the omni channel case alone. Customer's source of purchase, supplier selection and other costs are discussed for three cases. For the risk/sensitivity analysis, 5\% price increase in retailer's selling price is considered.

\subsection{Omni Channel related intermediate outputs}

The total quantity manufactured is more than that supplied because there are products coming from the recycling center to the manufacturer to be repaired and remanufactured, shown in table 2. 
Table 1. Input parameters and range.

\begin{tabular}{|c|c|c|c|c|c|}
\hline Capacity parameters & Range in units & Cost parameters & Range in Rs & Distance parameters & Range in distance units \\
\hline$P_{i k}^{\max }$ & $300-400$ & $C_{i k}$ & $850-1000$ & $d_{j f}$ & $15-50$ \\
\hline$P_{i k}^{\min }$ & $35-50$ & $T_{i j}$ & $7-10$ & $d_{l f}$ & $15-50$ \\
\hline$R_{s k}$ & 1 & $T_{j l}$ & $7-10$ & $d_{l m}$ & $15-50$ \\
\hline$P_{j s}$ & $275-400$ & $D_{c l}^{I n v}$ & $5-6$ & Dis & $15-50$ \\
\hline$P C_{j s}$ & $50-80$ & $P^{s p}$ & 1225 & $E M$ & $9-13$ \\
\hline$D L_{s}$ & $150-350$ & $D^{s p}$ & 1300 & & \\
\hline$D^{I n i I n v}$ & zero & $R^{s p}$ & 1400 & Customer demand & Range in units \\
\hline$R E C^{\text {InitInv }}$ & 0 & $T_{j f}$ & $4-6$ & $D_{a}$ & $10-75$ \\
\hline$R t_{m}$ & $300-350$ & $T_{l f}$ & $4-6$ & $D_{b}$ & $10-75$ \\
\hline$R^{\text {InitInv }}$ & 0 & $T_{l m}$ & $4-6$ & $D_{c}$ & $30-75$ \\
\hline$R E C^{\max }$ & $250-300$ & $R_{c}^{I n v}$ & $2-3$ & & \\
\hline \multirow[t]{2}{*}{ Veh } & $15-25$ & $T R_{q j k}$ & $3-5$ & & \\
\hline & & $R E C_{c}^{I n v}$ & $2-3$ & & \\
\hline
\end{tabular}

Table 2. Quantity manufactured in 10 different instances.

\begin{tabular}{lcccccccccc}
\hline & 1 & 2 & 3 & 4 & 5 & 6 & 7 & 8 & 9 \\
\hline M1 & - & 40 & 30 & - & - & 100 & - & 90 & - \\
M2 & - & - & 40 & 40 & 40 & 50 & 75 & - & 35 \\
M3 & - & 30 & 200 & 195 & 165 & 124 & 75 & 30 & 135 \\
\hline
\end{tabular}

Table 3 shows that the quantity transported from plant to warehouse, is more or less evenly spaced.

The above table 4 clearly states that there is no movement of products from warehouse ' 2 '. The difference between the total quantity transported between manufacturer to warehouse (339) and that from the warehouse to retailer (339) is zero as no inventory is stored in the warehouse during the $10^{\text {th }}$ time period.

Table 3. Quantity transported from manufacturer to warehouse.

\begin{tabular}{lccc}
\hline Manufacturer & Warehouse & Time period & Quantity transported \\
\hline 2 & 3 & 3 & 10 \\
2 & 3 & 4 & 30 \\
2 & 3 & 5 & 40 \\
3 & 1 & 4 & 70 \\
3 & 1 & 5 & 65 \\
3 & 1 & 6 & 124 \\
\hline
\end{tabular}

Table 4. Quantity transported from warehouse to retailer.

\begin{tabular}{lccc}
\hline Warehouse & Retailer & Time period & Quantity transported \\
\hline 1 & 1 & 5 & 70 \\
1 & 1 & 6 & 65 \\
1 & 1 & 7 & 124 \\
3 & 1 & 5 & 40 \\
3 & 1 & 6 & 40 \\
\hline
\end{tabular}

\subsection{Customer's source of purchase}

Retailer price is increased for the omni channel case upto $5 \%$ and noticed that there is no change in the source of customer demand satisfaction. Customer demand is increased upto $20 \%$ for the omni channel case and observed no change in source of demand satisfaction, shown in table 5 .

\subsection{Supplier selection decision}

\section{3a Selection of supplier for Omni Channel:}

Selection of supplier for omni channel case is shown in table 6 . When increasing demand upto $20 \%$ and increasing the retailer price upto $5 \%$ which supplier has been chosen for different time periods is also shown in table 6. It is observed that there is no influence of demand and retailer price on supplier selection.

\section{3b Selection of supplier for Omni Channel without green} objective and traditional offline mode:

Selection of supplier for omni channel without green objective and offline mode is shown in table 7. It is observed that selection of supplier ' 4 ' is more economical if there is no green objective. Supplier' 2' has chosen most of the time periods for offline mode case.

The total customer demand and quantity of products ordered from the supplier don not add up as there are a lot of products being recycled and the entire supply chain is 
Table 5. Customer type and source of demand satisfaction.

\begin{tabular}{|c|c|c|c|c|c|}
\hline \multicolumn{2}{|c|}{ Customer type c } & \multicolumn{2}{|r|}{ Customer type d } & \multicolumn{2}{|r|}{ Customer type e } \\
\hline Customer & Source of demand satisfaction & Customer & Source of demand satisfaction & Customer & Source of demand satisfaction \\
\hline 1 & M3 & 1 & M3 & 1 & $\mathrm{R} 1$ \\
\hline 2 & M2 & 2 & M1 & 2 & $\mathrm{R} 1$ \\
\hline 3 & M2 & 3 & M3 & 3 & $\mathrm{R} 1$ \\
\hline 4 & M1 & 4 & M1 & 4 & $\mathrm{R} 1$ \\
\hline 5 & M1 & 5 & M3 & 5 & $\mathrm{R} 1$ \\
\hline
\end{tabular}

Table 6. Selection of supplier for omni channel case, omni channel with $20 \%$ Demand Increase and Omni Channel With $5 \%$ R 1 Price Increase.

\begin{tabular}{|c|c|c|c|c|c|c|c|c|c|c|c|}
\hline \multicolumn{4}{|c|}{ Omni channel } & \multicolumn{4}{|c|}{ With $20 \%$ demand increase } & \multicolumn{4}{|c|}{ With $5 \% \mathrm{R} 1$ price increase } \\
\hline$S$ & M & $\mathrm{TP}$ & Q & $\mathrm{S}$ & M & $\mathrm{TP}$ & Q & $\mathrm{S}$ & M & $\mathrm{TP}$ & Q \\
\hline 3 & 2 & 2 & 40 & 3 & 2 & 2 & 40 & 3 & 2 & 2 & 40 \\
\hline 3 & 2 & 3 & 40 & 3 & 2 & 3 & 40 & 3 & 2 & 3 & 40 \\
\hline 3 & 2 & 4 & 40 & 3 & 2 & 4 & 40 & 3 & 2 & 4 & 40 \\
\hline 3 & 2 & 5 & 40 & 3 & 2 & 5 & 40 & 3 & 2 & 5 & 40 \\
\hline 3 & 2 & 6 & 75 & 3 & 2 & 6 & 90 & 3 & 2 & 6 & 75 \\
\hline 3 & 3 & 6 & 75 & 3 & 3 & 6 & 90 & 3 & 3 & 6 & 75 \\
\hline 3 & 3 & 8 & 40 & 3 & 3 & 8 & 40 & 3 & 3 & 8 & 40 \\
\hline 4 & 1 & 1 & 35 & 4 & 1 & 1 & 35 & 4 & 1 & 1 & 35 \\
\hline 4 & 1 & 7 & 81 & 4 & 1 & 7 & 105 & 4 & 1 & 7 & 81 \\
\hline 4 & 1 & 9 & 35 & 4 & 1 & 9 & 35 & 4 & 1 & 9 & 35 \\
\hline 4 & 1 & 10 & 35 & 4 & 1 & 10 & 35 & 4 & 1 & 10 & 35 \\
\hline
\end{tabular}

*S-Supplier; *M-Manufacturer; *TP-Time Period; *Q-Quantity ordered

Table 7. Selection of supplier selection for omni channel case, Omni Channel without Green Objective and offline mode case

\begin{tabular}{|c|c|c|c|c|c|c|c|c|c|c|c|}
\hline \multicolumn{4}{|c|}{ Omni channel } & \multicolumn{4}{|c|}{ Omni channel without green objective } & \multicolumn{4}{|c|}{ Offline mode } \\
\hline $\mathrm{S}$ & M & $\mathrm{TP}$ & Q & $S$ & M & $\mathrm{TP}$ & Q & $S$ & M & $\mathrm{TP}$ & Q \\
\hline 3 & 2 & 2 & 40 & 4 & 1 & 1 & 40 & 2 & 2 & 1 & 35 \\
\hline 3 & 2 & 3 & 40 & 4 & 1 & 3 & 10 & 2 & 2 & 2 & 35 \\
\hline 3 & 2 & 4 & 40 & 4 & 1 & 5 & 50 & 2 & 2 & 3 & 35 \\
\hline 3 & 2 & 5 & 40 & 4 & 1 & 6 & 35 & 2 & 2 & 4 & 35 \\
\hline 3 & 2 & 6 & 75 & 4 & 1 & 7 & 35 & 2 & 2 & 5 & 35 \\
\hline 3 & 3 & 6 & 75 & 4 & 1 & 9 & 35 & 2 & 2 & 6 & 35 \\
\hline 3 & 3 & 8 & 40 & 4 & 1 & 10 & 35 & 2 & 2 & 7 & 35 \\
\hline 4 & 1 & 1 & 35 & 4 & 3 & 2 & 100 & 2 & 2 & 8 & 35 \\
\hline 4 & 1 & 7 & 81 & 4 & 3 & 3 & 25 & 2 & 2 & 9 & 35 \\
\hline 4 & 1 & 9 & 35 & 4 & 3 & 4 & 50 & 4 & 1 & 10 & 35 \\
\hline 4 & 1 & 10 & 35 & 4 & 3 & 8 & 35 & 2 & 2 & 1 & 35 \\
\hline
\end{tabular}

*S-Supplier; *M-Manufacturer; *TP-Time Period; *Q-Quantity ordered

optimized for a limited number of time periods, hence there are many products at the retailer, warehouse and the manufacturer inventory at the end of the time horizon considered.The percentage increase in total supply chain cost due to an increase of $20 \%$ customer demand is $14.72 \%$.
Similarly, the increase in the total supply chain cost due to a $5 \%$ increase in selling price of retailer ' 1 ' is $0.35 \%$. The total supply chain cost decreases by $32.44 \%$ for offline only scenario when compared to the omni channel case, shown in figure 2. 


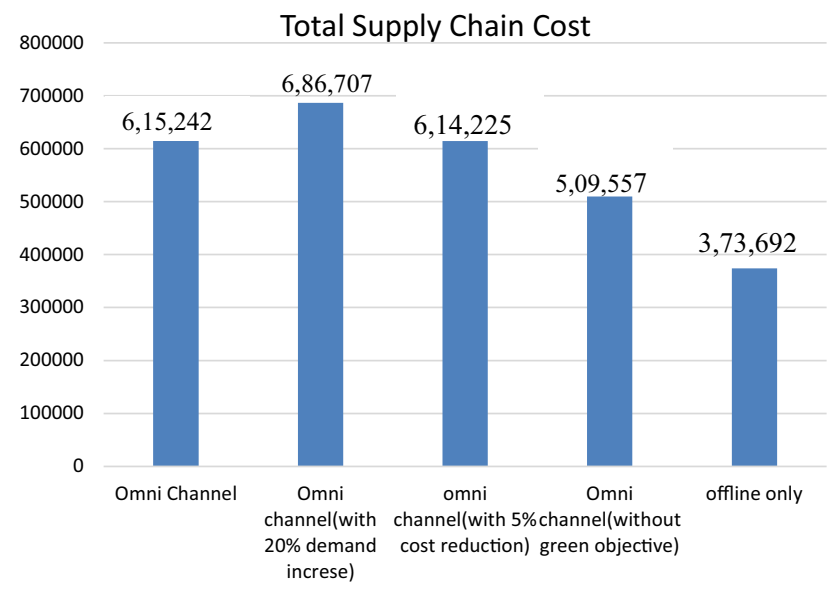

Figure 2. Total supply chain cost for different network configurations.

\section{Conclusions}

In this work, the mathematical model was formulated for the proposed multi period omni channel supply chain network. Then, Mixed Integer Programming model using CPLEX optimization software is used for solving it. The study focuses on generating an effective omni channel supply chain network to balance economic benefits and environmental cost. As was seen in the results, the customers sometimes prefer a particular offline or online source for buying. But this makes most of the sources obsolete as customers prefer only a select few of all the available options, like warehouses were not used at all and except for retailer 1, the other two were unused, hence reducing their product cost or shutting down of their operations if they can notmake profit, reducing the prices should be undertaken for an efficient, lean and cost effective supply chain. If the customer demand increases or the demographics vary, certain other set of sources might be useful and others to be closed down.

The 5\% increase in the retailer 1's selling price does not seem to have a significant change in the raw material or the total supply chain cost or even the emissions whereas there is a significant difference for the $20 \%$ demand increase case as expected as the total number of products to be delivered to the customer increases which in turn increases the emissions and the costs. The traditional offline scenario though seeming to incur way lesser costs for raw materials and the total supply chain costs, also not considering the green objective does not have a significant impact on the total supply chain costs incurred, but the raw material costs seem to be on the lower side when compared to the omni channel scenario. The most important significance of this work is that scenarios that cannot be visualized clearly due to its practical restrictions can be analyzed by simulating it using this model over various predefined time periods considering multiple channels.
In the present work, demand from the customers is assumed as deterministic in nature but generally even after extensive market research and forecasting, customer's demand usually ends up being stochastic in nature. More accurate representation of continuous time periods might be considered unlike the discrete time representation here. Many more objectives can be included and solved as a goal programming problem.

\section{References}

[1] Swaminathan J M and Tayur S R 2003 Models for supply chains in e-business. Manag. Sci. 49(10): 1387-1406

[2] Agatz N A, Fleischmann M and Van Nunen J A 2008 E-fulfillment and multi-channel distribution-a review. Eur. J. Oper. Res. 187(2): 339-356

[3] Lal R and Sarvary M 1999 When and how is the Internet likely to decrease price competition? Mark. Sci. 18(4): 485-503

[4] King R C, Sen R and Xia M 2004 Impact of web-based e-commerce on channel strategy in retailing. Int. J. Electron. Commun. 8(3): 103-130

[5] Bernstein F, Song J S and Zheng X 2008 "Bricks-and-mortar" vs "clicks-and-mortar": an equilibrium analysis. Eur. J. Oper. Res. 187(3): 671-690

[6] Farahani R Z and Elahipanah M 2008 A genetic algorithm to optimize the total cost and service level for just-in-time distribution in a supply chain. Int. J. Prod. Econ. 111(2): 229-243

[7] Biswas T and Samanta S 2016 A strategic decision support system for logistics and supply chain network design. Sādhanā 41(6): 583-588

[8] Fleischmann M, Van Nunen J A and Gräve B 2003 Integrating closed-loop supply chains and spare-parts management at IBM. Interfaces 33(6): 44-56

[9] Amin S H and Zhang G 2014 Closed-loop supply chain network configuration by a multi-objective mathematical model. Int. J. Bus. Perform. Supply Chain Model. 6(1): 1-5

[10] Keyvanshokooh, E, Sarah M R, and Elnaz K 2016 Hybrid robust and stochastic optimization for closed-loop supply chain network design using accelerated Benders decomposition. Eur. J. Oper. Res. 249(1): 76-92

[11] Gaur J, Amini M and Rao A K 2017 Closed-loop supply chain configuration for new and reconditioned products: an integrated optimization model. Omega 66: 212-223

[12] Elhedhli S and Merrick R 2012 Green supply chain network design to reduce carbon emissions. Transp. Res. Part D: Transp. Environ. 17(5): 370-379

[13] Tao Z G, Guang Z Y, Hao S and Song H J 2015 Multi-period closed-loop supply chain network equilibrium with carbon emission constraints. Resour. Conserv. Recycl. 104: 354-365

[14] Lam J S and Gu Y 2016 A market-oriented approach for intermodal network optimization meeting cost, time and environmental requirements. Int. J. Prod. Econ. 171: 266-274

[15] Nouira I, Hammami R, Frein Y and Temponi C 2016 Design of forward supply chains: impact of a carbon emissionssensitive demand. Int. J. Prod. Econ. 173: 80-98 
[16] Colicchia C, Creazza A, Dallari F and Melacini M 2016 Ecoefficient supply chain networks: development of a design framework and application to a real case study. Prod. Plan. Control 27(3): 157-168

[17] Cummins S, Peltier J W and Dixon A 2016 Omni-channel research framework in the context of personal selling and sales management: a review and research extensions. J. Res. Interact. Mark. 10(1): 2-16

[18] Picot-Coupey K, Huré E and Piveteau L 2016 Channel design to enrich customers' shopping experiences: Synchronizing clicks with bricks in an omni-channel perspective-the Direct Optic case. Int. J. Retail Distrib. Manag. 44(3): 336-368

[19] Hübner A, Kuhn H and Wollenburg J 2016 Last mile fulfilment and distribution in omni-channel grocery retailing: a strategic planning framework. Int. J. Retail Distrib. Manag. 44(3): 228-247
[20] Bortolini M, Faccio M, Ferrari E, Gamberi M and Pilati F 2016 Fresh food sustainable distribution: cost, delivery time and carbon footprint three-objective optimization. J. Food Eng. 174:56-67

[21] Mogale D G, Kumar M., Kumar S K and Tiwari M K 2018 Grain silo location-allocation problem with dwell time for optimization of food grain supply chain network. Transp. Res. Part E: Logist. Transp. Rev. 111: 40-69

[22] Mogale D G, Lahoti G, Jha S B, Shukla M, Kamath N and Tiwari M K 2018 Dual market facility network design under bounded rationality. Algorithms 11(4): 54

[23] Costantini V, Crespi F, Marin G and Paglialunga E 2017 Ecoinnovation, sustainable supply chains and environmental performance in European industries. J. Clean. Prod. 155: 141-154

[24] Arampantzi C and Minis I 2017 A new model for designing sustainable supply chain networks and its application to a global manufacturer. J. Clean. Prod. 156: 276-292 